\title{
Indications and Results of Surgical Treatment of Proximal Femoral Fractures in Adults at Ouagadougou
}

\author{
S. C. Da, H. Kafando, A. S. Korsaga, S. Tinto, A. Wangrawa, M. Tall \\ Centre Hospitalier Universitaire Yalgado Ouédraogo (CHU YO), Ouagadougou, Burkina Faso \\ Email: chnyo@fasonet.bf
}

How to cite this paper: Da, S.C., Kafando, H., Korsaga, A.S., Tinto, S., Wangrawa, A. and Tall, M. (2018) Indications and Results of Surgical Treatment of Proximal Femoral Fractures in Adults at Ouagadougou. Open Journal of Orthopedics, 8, 200-212. https://doi.org/10.4236/ojo.2018.85023

Received: March 19, 2018

Accepted: May 21, 2018

Published: May 24, 2018

Copyright $\odot 2018$ by authors and Scientific Research Publishing Inc. This work is licensed under the Creative Commons Attribution International License (CC BY 4.0).

http://creativecommons.org/licenses/by/4.0/

\begin{abstract}
Background: Functional treatment of proximal femur fractures (PFF) is being discontinued with advances in surgery and anesthesia. Suspension traction is used as a waiting treatment before surgery when technical, material and financial conditions are not met. The surgical treatment of these fractures must ensure a stable reduction and fixation, to allow early support to the patient who will quickly regain his previous autonomy. Objective: To specify the indications for surgical treatment of proximal fractures in adult in order to evaluate the results in the context of Burkina Faso. Patients and Methods: We conducted a retrospective study including adult patients hospitalized and followed up for proximal femoral fracture (PFF) in the orthopedic-traumatology department of the Yalgado Ouedraogo University Hospital Center at Ouagadougou. Among 310 patients presenting with PFF in 5.5 years, (56 cases a year (10.4\%)), we focused on those whose PFFs were treated by surgical methods and followed up. Patients treated with orthopedic (40.1\%) or functional (6.8\%) methods, patients with incomplete records and those having signed a discharge against medical advice were excluded. A total of 94 patients, with 95 PFFs treated by surgical methods, constituted our study population. Road traffic accidents (51.1\%) and domestic accidents (48.9\%) were the predominant etiologies. The functional criteria of Postel Merle d'Aubigné (PMA) were used for the evaluation of the results (Table 1). Results: A total of 65 men and 29 women (sex ratio 2.2), aged of average 56 years, were recorded. Trochanteric mass fractures were predominant with 63 cases (66.3\%), including one case of bilateral fracture and one case of an open fracture; we also reported 32 femoral neck fractures (33.7\%). Osteosynthesis was performed in 66 patients (70.2\%) and hip arthroplasty in the remaining 28 patients (29.8\%). Osteosynthesis with DHS plate screws was performed in 49 cases $(73.1 \%)$ and Moore type cephalic arthroplasty in 18 cases $(64.3 \%)$. Two patients $(2.1 \%)$ died, one
\end{abstract}


in shock state and the second by pulmonary embolism. The main complications were 3 superficial infections (3.16\%), 10 painful coxitis (35.7\%) and one pseudarthrosis (dismantling of the material). Despite these complications, functional outcomes were satisfactory in $88.7 \%$, poor in $9.7 \%$ and fair in $1.6 \%$. Conclusion: Surgical treatment of proximal femoral fractures allows early removal and rapid functional rehabilitation; which improves functional outcomes and increases the quality of life in elderly patients.

\section{Keywords}

Fractures, Proximal Extremity, Femur, Treatment

\section{Introduction}

Currently surgical treatment of proximal femoral fractures (PFF) is no longer discussed. It ensures a stability in reduction and fixation to allow early support to the patient who will quickly regain his former autonomy [1].

Osteosynthesis with intramedullary support by gamma nail, was born from the inadequacies of the nail Ender and problems it creates in the knee and its lack of stability. Developed at the Center for Traumatology and Orthopedics in Strasbourg, long gamma nails are available for certain subtrochanteric and trochanterodiaphyseal fractures. Osteosynthesis with extra-medullary support by Mac Laughlin's plate nail is easy to set up and its average duration of surgery is shorter than with the blade-plate. However, it is a fragile semi-rigid system. Secondary disassembly or unscrewing is not exceptional. Charging and walking are not possible for three months. Robert Judet's screw-plate is intended for the osteosynthesis of proximal femoral and distal femoral fractures. Currently, Dynamic Hip Screw (DHS) is the most used material for osteosynthesis of per-trochanteric fractures. Austin Moore's, J.R. Judet's, Thompson's arthroplasty by cephalic prostheses [2], is an elegant means of eliminating the risks of osteosynthesis, avoiding the reinterventions of elderly's displaced femoral neck fractures. It has its own risks and complications. The intermediate prosthesis or bipolar prosthesis, or even the total prosthesis can reduce these pitfalls. But their expensive cost is not within the reach of patients without social security system.

Numerous Western studies have reported the high frequency of fractures of the proximal femur in adults. Massin [3] points out that osteosynthesis of a well-reduced intra-capsular fracture minimizes the risk of the femoral head necrosis. According to Georgiannos et al. [4], the complications of subtrochanteric fractures treated with long-nailed Gamma 3 (LG3N) are lower (12\%) than those treated with long-term classic Trochanteric Gamma (LTGN2) nail (24\%). In addition, the rate of resumption of osteosynthesis is greater (20.4\%) with the LTGN2 implant than with LG3N. Dynamic osteosynthesis of pertrochanteric fractures allows earlier recovery of walking and improves functional prognosis. But the fixation of unstable trochanteric fractures must be further improved. 
Helin et al. [5] specify that the use of the PFNA nail allows the fixation of pertrochanteric fractures with a success rate similar to those published with other materials. In the elderly, arthroplasty for intra-capsular fractures must be carried out with the utmost care, in order to reduce their mortality and morbidity rate. According to Larbi et al. [6], 80\% of these fractures occur in women over the age of 70 (mean age 81 years); for men over 70 (mean age 78 ), this rate is $50 \%$. In our context, few studies have focused on the surgical indications of proximal femoral fractures (PFF). Da et al. in 2002 [7], carried out the first study on DHS plate screws osteosynthesis of fractures of the proximal femur in Ouagadougou. In 2009, Da et al. [8], reported the results of 36 hip prostheses for femoral neck fracture in Ouagadougou.

Through this study, we want to evaluate the functional results of the surgical treatment of PFF, in order to improve its management in our context.

\section{Patients and Methods}

We undertook a retrospective descriptive study in the orthopedic-traumatology department of the Yalgado Ouedraogo University Hospital Center, between January 2007 and June 2012. Data were collected from clinical records, consultation records and medical consolidation certificates on a regular basis during 4 months. These data were analyzed using the software Epi info version 7.0.9.7. The graphics were done by converting the data to the Excel software. A total of 310 patients presenting with PFF, were hospitalized during 5.5 years, as an annual occurrence of 56 cases (10.4\%). Among them, we focused on 94 patients with 95 PFF treaded by surgical methods and followed up. Patients with incomplete records, patients who signed a discharge against medical advice, patients not followed in the department and those who received orthopedic or functional treatment (83 patients) were not included in the study. Road traffic accidents (51.1\%) and domestic accidents (48.9\%) predominated. Sixty-five men (69.1\%) and 29 women (30.9\%), (sex ratio 2.2), with an average age of 56 years (range, 24 to 85 years) were identified. Twenty-six of our patients (27.7\%) were over 74 years old. Housewives (26.6\%), employees (17\%), farmers (16\%), retirees (14.9\%), traders (7.4\%) paid the highest price in PFF. Twenty-seven patients (28.7\%) had at least one tare on admission (19 cases of hypertension, 4 cases of diabetes, 2 cases of asthma and 2 cases of epilepsy).

The functional criteria of Postel Merle d'Aubigné (PMA) resented by rating, pain, mobility and walking (Table 1) allowed the evaluation of our results [9].

Excellent results scored $=18$; very good results scored $=17$; good results scored $=16$; fair results scored $=14-15$; poor results scored $=10-11-12-13$ and bad results scored $\leq 9$.

\section{Results}

The right pelvic limb was affected in 51 cases $(54.3 \%)$, the left in 42 cases (44.7\%); a case of bilateral involvement was noted. According to the Gustillo and 
Table 1. Postel Merle d'Aubigné functional index (PMA) [9].

\begin{tabular}{|c|c|c|c|}
\hline Rating & Pain & Mobility & Walking \\
\hline 1 & $\begin{array}{l}\text { Very sharp pain when walking, } \\
\text { preventing activity and night pain }\end{array}$ & $\begin{array}{l}\text { Extreme stiffness } \\
\text { with a vicious atti- } \\
\text { tude }\end{array}$ & Only with canes \\
\hline 2 & Sharp pain during walking & $\begin{array}{l}\text { Flexion: } 40^{\circ} \\
\text { Abduction: } 0^{\circ} \text { with } \\
\text { vicious attitude }\end{array}$ & Only with two canes \\
\hline 3 & $\begin{array}{l}\text { Sharp pain, but allowing limited } \\
\text { activity }\end{array}$ & $\begin{array}{l}\text { Flexion: } 40^{\circ}-80^{\circ} \\
\text { Abduction: } 0^{\circ}\end{array}$ & $\begin{array}{c}\text { Limited with a cane (less than } 1 \mathrm{~h} \text { ), } \\
\text { very difficult without cane, light } \\
\text { claudication }\end{array}$ \\
\hline 4 & $\begin{array}{l}\text { Pain during and after walking, } \\
\text { disappearing quickly by rest }\end{array}$ & $\begin{array}{l}\text { Flexion: } 90^{\circ} \\
\text { Abduction: } 20^{\circ}\end{array}$ & $\begin{array}{l}\text { Prolonged with a cane, limited } \\
\text { without cane, light claudication }\end{array}$ \\
\hline 5 & $\begin{array}{l}\text { Very mild and intermittent pain } \\
\text { that does not prevent normal } \\
\text { activity }\end{array}$ & $\begin{array}{c}\text { Flexion: } 90^{\circ} \\
\text { Abduction: up to } 25^{\circ}\end{array}$ & $\begin{array}{l}\text { Without a cane, slight claudication, } \\
\text { only with fatigue }\end{array}$ \\
\hline 6 & Complete indolence & $\begin{array}{c}\text { Flexion: } 90^{\circ} \\
\text { Abduction: up to } 25^{\circ}\end{array}$ & Normal \\
\hline
\end{tabular}

Anderson classification, three patients (3.2\%) had an open type II trochanteric fracture. Trochanteric fractures predominated (59 cases: $62.1 \%$ ) with a bilateral fracture and an open fracture. Thirty-six femoral neck fractures (37.9\%) were observed (Table 2).

Trochanteric fractures were significantly more common $(41.1 \%)(p<0.0001)$; It was one bilateral fracture and one open fracture. The femoral neck was the second most common location (37.9\%).

Fourteen femoral neck fractures (14.74\%) were observed in women, whereas trochanteric fractures predominated in men (28.42\%) (Table 3).

There was no significant difference between the location of PFF by sex $(p=$ 0.3385).

According to Garden's classification, type IV femoral neck fractures were significantly more frequent $(75 \%)(P<0.0001)$ (Table 4$)$.

According to the AO classification, extra-articular type A2 fractures predominated (41.1\%), followed by those of type A1 (17.9\%). All femoral neck fractures were type B according to AO (37.9\%) (Table 5).

The 59 trochanteric fractures are listed according to the Ender classification in Table 6.

Type III fractures were the most represented (64.4\%), followed by type II $(15.3 \%)$ and type I $(10.2 \%)(p<0.0001)$ (Table 6).

Twenty-one traumatic injuries $(22.1 \%)$ including two poly traumas and 14 poly fractures were associated in 16 patients (17.2\%). Fractures of the femoral diaphysis (10 cases), floating knee syndrome (4 cases) and radial fractures (3 cases) were the predominant associated lesions (Table 7).

The average preoperative time was 22 days (range 1 to 69 days). It was 10 days 
Table 2. Distribution of poximal femoral fractures by location $(n=95)$.

\begin{tabular}{cccc}
\hline Location & Effectif & $\%$ & $P$ \\
\hline Femoral neck & 36 & 37.9 & \\
Trochanteric Massive & 39 & 41.1 & \\
Subtrochanteric region & 16 & 16.8 & $P<0.0001$ \\
Trochanteric-diaphyseal & 4 & 4.2 & \\
Total & 95 & 100 & \\
\hline
\end{tabular}

Table 3. Distribution of poximal femoral fractures by sex and location $(n=95)$.

\begin{tabular}{cccccc}
\hline \multirow{2}{*}{ Fracture location } & \multicolumn{2}{c}{ Male } & \multicolumn{2}{c}{ Female } & $P$ value \\
\cline { 2 - 5 } & Number & $\%$ & Number & $\%$ & \\
\hline Femoral neck & 22 & 23.15 & 14 & 14.74 \\
Trochanteric mass & 27 & 28.42 & 12 & 12.63 & $0.3385^{*}$ \\
Subtrochanteric region & 13 & 13.7 & 3 & 3.15 & 0 \\
Trochanteric-diaphyseal & 4 & 4.21 & 0 & 30.52 & \\
Total & 66 & 69.48 & 29 & &
\end{tabular}

Table 4. Distribution of femoral neck fractures according to Garden's classification ( $\mathrm{n}=$ $35)$.

\begin{tabular}{cccc}
\hline Type & Number & $\%$ & $P$ \\
\hline I & 1 & 2.8 & \\
II & 5 & 13.9 & \\
III & 3 & 8.3 & $P<0.0001$ \\
IV & 27 & 75 & \\
Total & 36 & 100 & \\
\hline
\end{tabular}

Table 5. Distribution of poximal femoral fractures according to AO classification ( $\mathrm{n}=$ 95).

\begin{tabular}{cccc}
\hline Type & Number & $\%$ & $P$ \\
\hline Extra articular or type A fractures: & 59 & 62.1 & \\
Simple fractures of the trochanteric region: A1 & 17 & 17.9 & $p<0.0001$ \\
Multiple pertrochanteric fractures: A2 & 39 & $31.1 \%$ & \\
Intertrochanteric fractures: type A3 & 3 & 37.9 & $p<0.0001$ \\
Intraarticular fractures or type B: & 36 & 0 & $100 \%$ \\
Fractures of the femoral head or type C & 0 & 95 &
\end{tabular}

Table 6. Distribution of trochanteric fractures according to Ender $(n=59)$.

\begin{tabular}{cccc}
\hline Type & Number & $\%$ & $P$ \\
I & 6 & 10.2 & \\
II & 9 & 15.3 & \\
III & 38 & 64.4 & $p<0.0001$ \\
IV & 2 & 3.4 & \\
V & 1 & 1.7 & \\
VI & 3 & 5 & \\
\hline
\end{tabular}




\section{Continued}

\begin{tabular}{ccc}
\hline VII & 0 & 0 \\
VIII & 0 & 0 \\
Total & 59 & 100 \\
\hline
\end{tabular}

Table 7. Distribution of associated traumatic injuries.

\begin{tabular}{cccc}
\hline Associated lesions & Number & $\%$ & $P$ \\
\hline Fractures of the femoral diaphysis & 10 & 47.6 & \\
Floating knee syndrome & 4 & 19 & $P<0.0001$ \\
Fractures of the radius & 3 & 14.3 & \\
Traumatic brain injury & 2 & 9.5 & \\
Coxo-femoral dislocation & 1 & 4.8 & \\
Tibial fracture & 1 & 4.8 & \\
Total & 21 & 100 & \\
\hline
\end{tabular}

for femoral neck and subtrochanteric fractures, 22 days for trochanteric fractures and 25 days for femoral neck fractures.

Osteosynthesis was performed in 67 PFF (70.5\%). DHS plate screw was used in 49 PFF (51.6\%) (Figure 1).

NB: Bilateral osteosynthesis using DHS's plate-screw was performed in one patient (Figure 2).

The arthroplasty (Figures 3-5) was performed in 28 patients with a predominance of the Moore's cephalic prosthesis (18 cases: 64.3\%) (Figure 6).

Functional rehabilitation was practiced in all our patients. The average length of hospital stay was 21.3 days (range 3 to 61 days). The average time to consolidate osteosynthated PFF was 3 months (range 2 to 7 months). It was 3 months for the trochanteric fractures and 4 months for the femoral neck fractures. Two cases of death $(2.1 \%)$ were recorded: the first case in a state of shock and the second case by pulmonary embolism. Four patients (4.3\%) were reoperated for malposition of the implant (three times of arthroplasty and resumption of osteosynthesis by DHS plate screw). The main complications were represented by 3 postoperative suppurations (3.3\%) cured by adapted antibiotherapy. Four vicious calluses (6\%), 3 limbs shortening (4.5\%) and nonunion (by disassembly of the synthetic material) were found among the syntheses of PFF and 10 painful coxitis (10.9\%) among arthroplasties. Sixty-two patients (67.4\%) were reviewed at an average follow-up of 36 months (range: 18 months and 66 months). Despite these complications, the functional results were satisfactory (88.7\%), fair (9.7\%) and poor (1.6\%) (Figure 7).

The functional results of the patients operated according to the sex and the seat of the fracture are illustrated in Table 8. DHS plate screw fixation provided 30 satisfactory results (48.39\%) including 10 excellent (16.13\%), 13 very good (20.97\%) and 7 good (11.29\%). The arthroplasty treatment provided 14 satisfactory results (22.58\%), including 4 excellent $(6.45 \%)$ and 10 very good (16.13\%) (Table 8). 


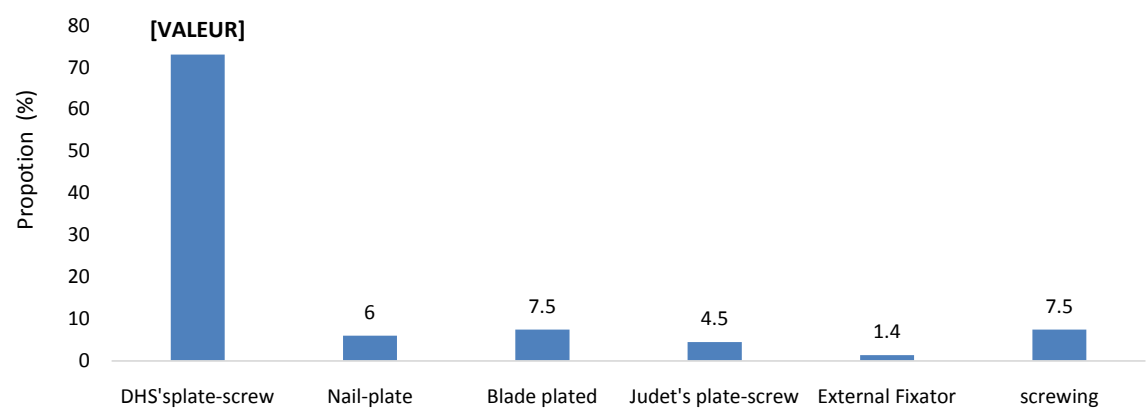

Figure 1. Distribution of patients according to type of implant used ( $\mathrm{n}=67)$. ( $p<$ $0.0001)$.

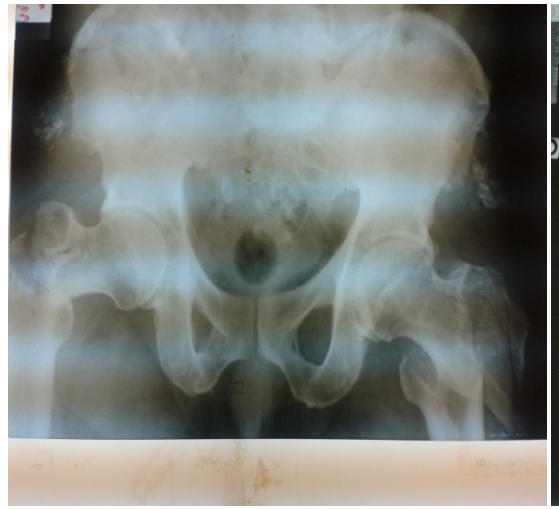

(a)

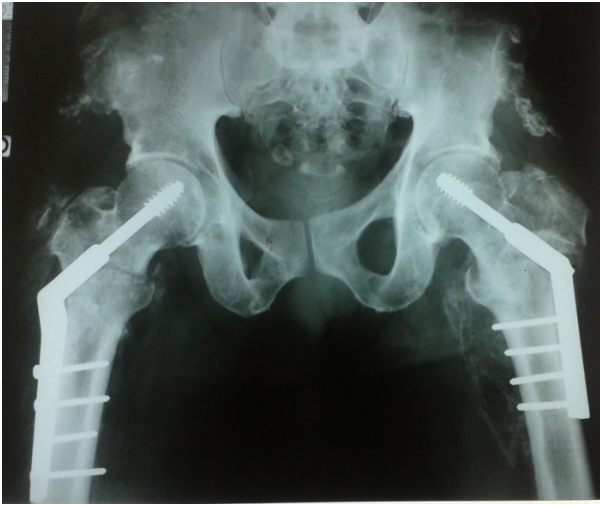

(b)

Figure 2. Pelvis anteroposterior radiograph in a 56-year-old man: (a) Pelvis anteroposterior radiograph showing a bilateral pertrochanteric fracture; (b) Immediate postoperative anteroposterior pelvic radiograph showing bilateral osteosynthesis using DHS's plate-screw.

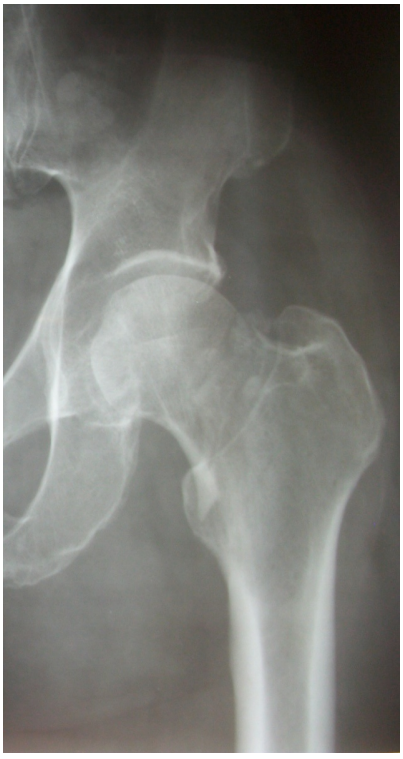

(a)

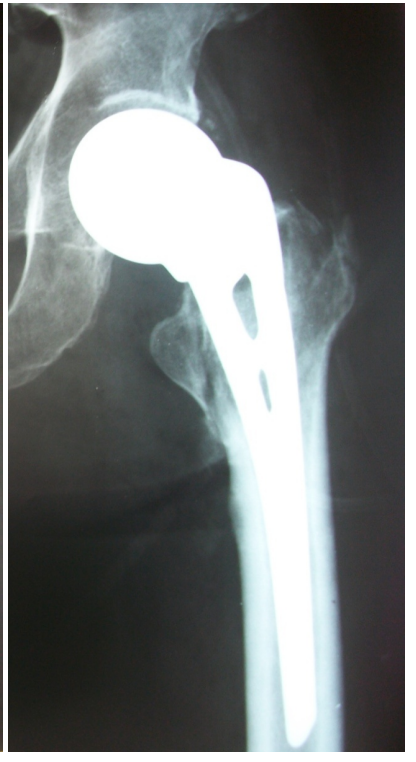

(b)

Figure 3. Hip anteroposterior radiograph of 82-year-old man: (a) Left femoral basal cervical fracture; (b) immediate postoperative radiographic showing Moore's arthroplasty. 


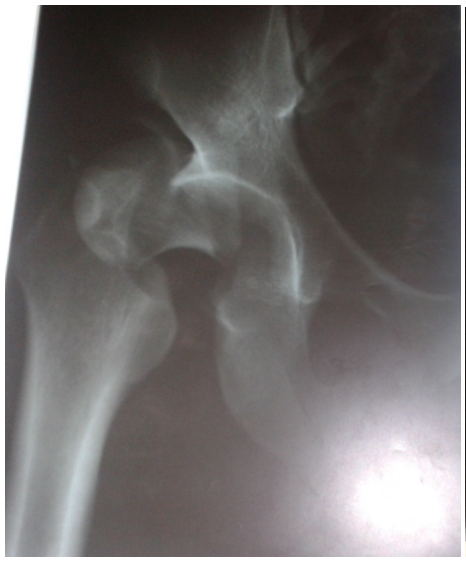

(a)

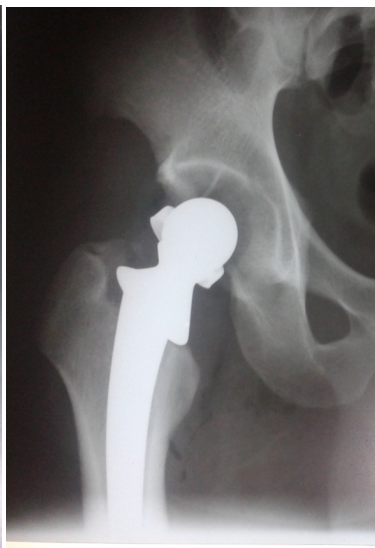

(b)

Figure 4. Anteroposterior radiograph of a 36 year-old man's hip: (a) Fracture of the right femoral neck type IV of Garden; (b) immediate postoperative radiograph showing intermediate arthroplasty.

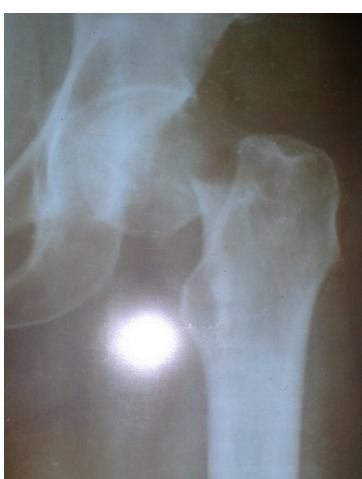

(a)

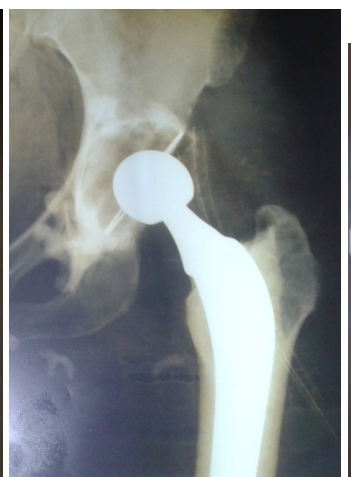

(b)

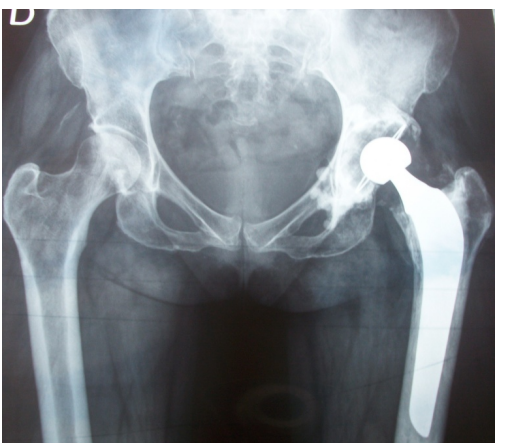

(c)

Figure 5. Anteroposterior radiograph of 60-year-old woman: (a) Fracture Garden IV of the left femoral neck; (b) immediate postoperative radiograph showing total hip arthroplasty; (c) postoperative radiographic at the follow-up of 9 months.

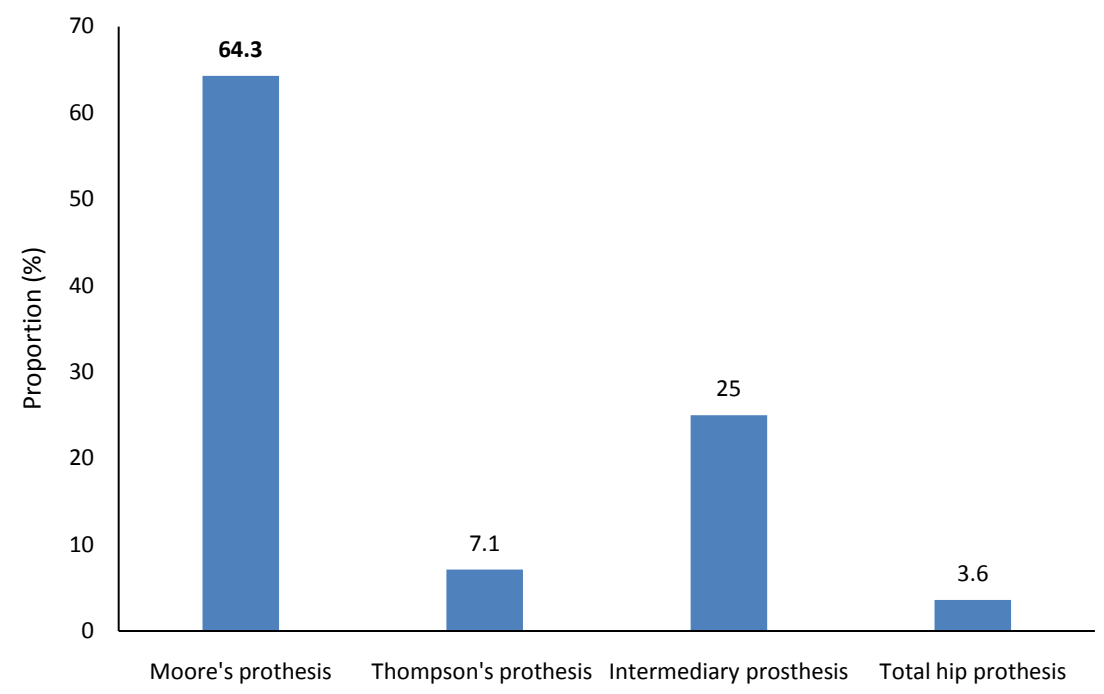

Figure 6. Distribution of patients according to the type of prosthesis. 


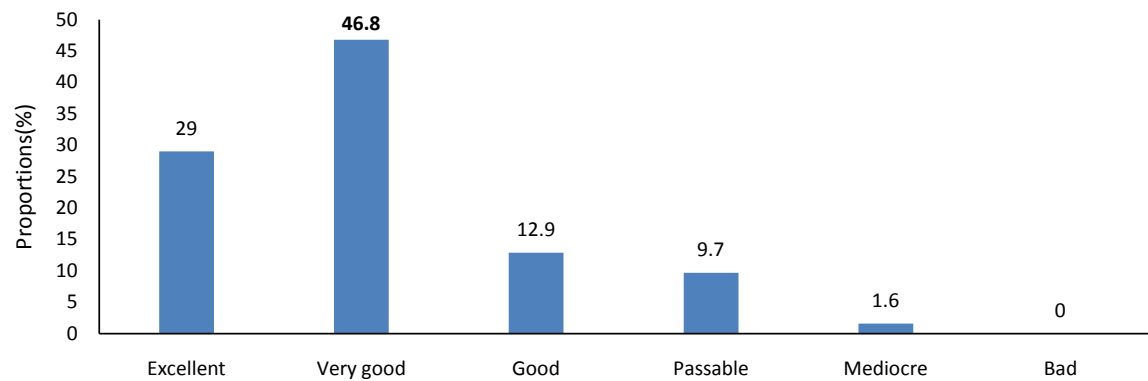

Figure 7. Functional results according to the PMA score at the average follow-up of 36 months $(n=62)$.

Table 8. Functional results by type of equipment used $(n=62)$.

\begin{tabular}{cccccccc}
\hline & Nail plate & $\begin{array}{c}\text { DHS plate } \\
\text { screw }\end{array}$ & $\begin{array}{c}\text { Screw Judet } \\
\text { plate }\end{array}$ & Blade plate & Screw & Prosthesis & Total \\
\hline Excellent & 1 & 10 & 1 & 0 & 2 & 4 & 18 \\
Very good & 2 & 13 & 1 & 1 & 2 & 10 & 29 \\
Good & 0 & 7 & 0 & 1 & 0 & 0 & 8 \\
Fair & 0 & 2 & 0 & 0 & 0 & 4 & 6 \\
Poor & 0 & 0 & 0 & 1 & 0 & 0 & 1 \\
Bad & 0 & 0 & 0 & 0 & 0 & 0 & 0 \\
Total & 3 & 32 & 2 & 3 & 4 & 18 & 62 \\
\hline
\end{tabular}

\section{Discussion}

The limits of our retrospective mono-centric series included:

1) loss of data after the exclusion of incomplete files for their incompleteness, for the departure against medical advice or for financial and cultural reasons;

2) for functional and orthopedic treatment. Indeed, surgical treatment is the ideal indication of PFF.

Our incidence of 56 patients with PFF, is overlapping that of Razafimahandry [10] who noted an average incidence of 54 cases per year. It is significantly lower than that of Morris [11] in 2002 and Aubrun [12] in 2011 with respectively 350,000 and 65,000 cases per year. Our population is also smaller and less aging than those of the authors of the industrialized countries. The young age of our patients (56 years old) is similar to those of $\mathrm{Da}$ et al. [7] [8], but lower than those of Rabemazava et al. [13] and Larbi et al. [6] in 2011, with respectively 64 and 81 years old. The young age of our series would be explained by the great youth of our population. The frequency of FFP increases with the age of the population. Our data corroborate those of Cordey et al. [14] who reported an exponential increase in PFF with age and especially from 50 years in men and 55 years in women. The male sex predominated (sex ratio 2.2) in our series; it is comparable to that of Razafimahandry et al. [10] with 1.7. Larbi et al. [6] noted a female predominance ( 3 women for $1 \mathrm{man}$ ). Male subjects were younger in our series (56 cases) compared to female subjects (68 cases) with a statistically significant 
difference $(p=0.00005)$. This is due to the high mobility of the male population, with the risk appetite and their characteristic recklessness: fractures most often occur in a context of violent trauma such as road traffic accidents. Femoral neck fractures $(48.3 \%)$, are related to minimal trauma by falling in height, due to postmenopausal osteoporosis (Table 3). Neglect, lack of financial means, sometimes ignorance of the patient and his entourage, motivate their first recourse to traditional therapists.

The frequency of fractures of the trochanteric (62.1\%) and femoral neck (37.9\%) of our series is comparable to that of Rabemazava et al. [13] with 50\% fractures of the trochanteric trunk and $40 \%$ fractures of the cervix. This finding corroborates the study of Féron et al. [15], who reported a fracture ratio of femoral neck and trochanteric mass of 1.4 in women and 1.5 in men. According to the AO classification, extra-articular type A2 fractures predominated (40\%) [16]. In our series, 16 patients (17\%) had associated lesions. Rabemazava et al. [13] reported 23.3\%. The lack of our technical platform and the lack of financial means for patients explain the high rate of functional and orthopedic treatment (46.9\%). Our rate is comparable to that of Razafimahandry et al. [9] with $62.3 \%$.

The treatment of PFF is most often surgical, except for multi-weighted or osteoporotic sites [14]. Surgical treatment was performed in $53.1 \%$ of our patients, with $70.5 \%$ osteosynthesis and $29.5 \%$ arthroplasty. DHS screw-plate osteosynthesis was performed in 49 cases (73.1\%). The arthroplasty was performed in $29.5 \%$, mainly using the Moore prosthesis (64.3\%) and the intermediate prosthesis (25\%).

According to Chang et al. [17] survival at one year of follow-up, is comparable in the case of intermediate arthroplasty for displaced cervical fracture than for unstable fracture of the trochanteric mass on osteoporosis of the elderly. We have no experience of using this type of arthroplasty for unstable trochanteric fractures.

Our rates are different from those of Rabemazava et al. [13] who found 28.3\% of surgical treatment including osteosynthesis in $87.7 \%$ of cases. In our series, osteosynthesis was the most performed with a preponderance of the use of the DHS screw-plate. We do not have Gamma nail, indicated especially in trochanteric fractures; By using this type of nail, we would have reduced the rate of mechanical complications. Indeed, Georgiannos et al. [2] have shown that this type of implant is effective for the treatment of trochanteric fractures because it causes fewer mechanical complications.

Our rates are different from those of $\mathrm{Da}$ et al. [7], because the cases in their series only focused on DHS screw-plate osteosynthesis in their first year of experimentation. The arthroplasty was performed 5 times a year in our series, whereas it was performed 3 times a year in the series of $\mathrm{Da}$ et al. [8]. These results are underestimated because of the large number of incomplete files and the patients who have come out against medical advice.

The overriding choice of the DHS screw-plate could be explained by:

1) the greatest frequency of fractures of the trochanteric massif in our series; 
2) the affordable cost of the synthetic implant and its availability compared to prostheses.

Joint replacement surgery is indicated mainly in displaced fractures of the femoral neck. But in the young subject, Hudson et al. [18] advocate osteosynthesis which gives good results. Moreover, in trochanteric fractures, DHS screw-plate or gamma nail osteosynthesis provides better results [19]. We did not have this type of implant in our therapeutic arsenal.

The average operative time of 22 days of our series, is longer than that Rabemazava et al. [13] with an average operative time of 13.3 days.

This long delay of our series could be explained by:

1) the long delay of consultation (5.3 days on average);

2) the time of the preoperative assessment (average of 7 days);

3) the insufficient number of orthopedic surgeons-traumatologists;

4) the non-availability of osteosynthesis equipment;

5) and the lack of financial means for patients who most often have no health insurance.

Scheerlinck and Haentjens [20] reported an ideal operating time of 48 hours.

The PFF surgery is performed as a regulated program after the management of vital emergencies. However, Cohen-Bittan et al. [21] stress the importance of the delay of surgery in the functional and vital prognosis.

Only 42 patients in our series had responded to the clinical radio control appointment, another 35 were contacted by phone The 17 patients (18.9\%) who were not seen at the last follow-up were represented by:

1) elderly patients with a reduced physical activity;

2) patients without pain and who did not want to come back for their control.

Our mortality rate of $2.1 \%$ is lower than that of Razafimahandry et al. [10] with $8.3 \%$ of hospital deaths. The rate of superficial infections $(3.2 \%)$ of our series is lower than those of Rabemazava et al. [13] with $23.3 \%$ and Da et al. [8] with $15 \%$.

The factors involved in the occurrence of surgical site infections are constituted, inter alia by the long operating delay, the long duration of surgical intervention, the non-compliance with aseptic measures and the uncontrolled flow of health personnel into surgery room. Late postoperative complications were dominated by coxitis, vicious callus and shortening of the pelvic limb. Marks et al. [22], noted a lower complication rate $(5 \%-10 \%)$ in patients treated by surgical method.

The functional results according to the PMA score [9] were excellent and very good in $77.4 \%$ of the cases in our series. DHS screw-plate osteosynthesis and arthroplasty performed best with $71.9 \%$ and $77.9 \%$, respectively.

\section{Conclusion}

The impact of PFF can be reduced by efforts to prevent traffic accidents. Surgical treatment allows early elevation and functional rehabilitation, improving func- 
tional outcomes. Despite our modest working conditions, surgical treatment has given us good results. The improvement of the surgical therapeutic methods passes by the improvement of our technical platform.

\section{References}

[1] Pibarot, V. and Bejui-Hugues, J. (2001) Fractures du massif trochantérien (prothèse fémorale exceptée). Encycl. Méd-Chir, Techniques chirurgicales, OrthopédieTraumatologie, 44-620, $13 \mathrm{p}$.

[2] Kempf, I., Dagrenat, D. and Karger, C. (1993) Fractures de l'extrémité supérieure du fémur. Editions Techniques. Encycl Med Chir Appareil Locomoteur, 14-076-A-10, $28 \mathrm{p}$.

[3] Massin, Ph. (2004) Les fractures de l'extrémité proximale du fémur. Maitrise d'Orthopédie mai].

[4] Georgiannos, D., Lampridis, V. and Bisbinas, I. (2015) Fractures sous-trochantériennes du fémur traitées par long clou Gamma 3: Une étude historique "en cas/contrôle" comparative avec le long clou trochantérique Gamma. RCOT, 101, 445-450.

[5] Hélin, M., Pelissier, A., Boyer, P., Delory, T., Estella, C. and Massin, P. (2015) Le clou PFNA permet-il de limiter l'impaction des fractures per trochantériennes du fémur proximal? Une étude "cas/contrôle" de 115 cas. RCOT, 101.

[6] Larbi, A., Blin, D. and Cyteval, C. (2011) Traumatismes de l'extrémité supérieure du fémur et du bassin chez le sujet âgé. Journal de radiologie, Elsevier Masson France, 92, 567-580.

[7] Da, S.C., Yilboudo, J., Nacoulma, S.I., Nana, J.N. and Compaoré, T. (2002) Résultats de 20 ostéosynthèses de fractures du col fémoral au CHU-YO (Burkina Faso). Burkina Medical, 5, 5-12.

[8] Da, S.C., Sawadogo, M., Kafando, H., Zan, A., Nacoulma, S.I. and Ouédraogo, R.K. (2009) Résultats de 36 prothèses de hanche pour fracture du col fémoral au CHU-YO de Ouagadougou. Burkina Médical, 13, 75-83.

[9] Merle D'aubigné, R. (1970) Cotation chiffrée de la fonction de la hanche. Revue de Chirurgie Orthopédique et Traumatologique, 56, 481-6.

[10] Razafimahandry, H.J.C., Rakoto-Ratsimba, H.N., Rabesalama, S. and Rakotozafy, G. (2006) Epidémiologie des fractures de l'extrémité supérieure du fémur chez l'adulte Médecine d Afrique Noire, $\mathrm{n}^{\circ}$ 5304, 233-237.

[11] Morris, A.H. and Zuckerman, J.D. (2002) National Consensus Conference on Improving the Continuum of Care for Patients with Hip Fracture. The Journal of Bone and Joint Surgery. American Volume, 84-A, 670-674.

[12] Aubrun, F. (2011) Fracture de l'extrémité supérieure du fémur du patient âgé: Aspect épidémiologique, facteurs de risque. Annales Françaises d Anesthésie et de Réanimation, Elsevier Masson France, 30, 41-43.

[13] Rabemazava, A.Z.L.A., Solofomalala, G.D., Tsiaviry, P. and Razafimahandry, H.J.C. (2011) Prise en charge chirurgicale des fractures du fémur proximal chez l'adulte au Centre Hospitalier Universitaire d'Antananarivo. Médecine d Afrique Noire, 58.

[14] Cordey, J., Schneider, M. and Buhler, M. (2000) Epidemiology of Fractures of the Proximal Femur. Injury, 31, 56-61. https://doi.org/10.1016/S0020-1383(00)80033-9

[15] Feron, J.M., Gleize, S. and Signoret, F. (2000) L'enclouage type Gamma des fractures de l'extrémité proximale du fémur. Springer Verlag, 66-72.

[16] Müller, M.E., Nazarian, S. and Koch, P. (1987) Classification AO des Fractures. 
Springer-Verlag, Berlin, Heidelberg, New York, 163 p.

https://doi.org/10.1007/978-3-662-06263-0

[17] Chang, J.D., Kim, I.S., Lee, S.S., Yoo, J.H. and Hwang, J.H. (2016) Arthroplastie intermédiaire de hanche pour fractures instables du massif trochantérien ou pour fracture cervicale déplacée. Étude cas témoin deux chortes de 80 cas. RCOT; Vol. 102.

[18] Hudson, J.I., Kenzora, J.E., Hebel, J.R., Gardinier, M.S., Scherlis, L., Epstein, R.S. and Magaziner, J.S. (1998) Eight Years Outcome Associates with Clinical Option in the Management of Femoral Neck Fractures. Clinical Orthopaedics and Related Research, 348, 59-66.

[19] Kosygan, K.P., Mohan, R. and Newman, R.J. (2002) The Gotfried Percutaneous Compression Plate Compared with the Conventional Classic Hip Screw for the Fixation of Intertrochanteric Fractures of the Hip. The Journal of Bone and Joint Surgery, 84, 19-22. https://doi.org/10.1302/0301-620X.84B1.11919

[20] Scheerlinck, T. and Haentjens, P. (2003) Fracture de l'extrémité supérieure du fémur chez l'adulte. Encycl Méd Chir, Appareil locomoteur, 14-075-A-10, 27 p.

[21] Cohen-Bittan, J., Forest, A. and Boddaert, J. (2011) Fracture du col du fémur et urgences gériatriques: Prise en charge, organisation et indicateurs. Annales Françaises d Anesthésie et de Réanimation, 30, 41-43. https://doi.org/10.1016/j.annfar.2011.07.003

[22] Marks, R., Allegrante, J.P., Mackenzie, C.R. and Lane, J.M. (2003) Hip Fractures among the Elderly: Cause, Consequences and Control. Ageing Research Reviews, 2, 57-93. https://doi.org/10.1016/S1568-1637(02)00045-4 